УДК 796.853.23

МЕТОДИКА ПОВЫШЕНИЯ ЭФФЕКТИВНОСТИ ТЕХНИКИ БРОСКА «ПОДХВАТ ПОД ДВЕ НОГИ»У ДЗЮДОИСТОК

${ }^{1}$ Бобровский В.А., ${ }^{2}$ Бобровский А.В., ${ }^{1,3}$ Гераськин А.А., ${ }^{4}$ Мошков М.К., ${ }^{5}$ Харахордин С.Е.

${ }^{\prime}$ Омский государственный технический университет, Oмск, e-mail: bobrovskiy.av@mail.ru;

${ }^{2}$ Омская академия МВД России, Омск, e-mail: bobrovskiy.av@mail.ru;

${ }^{3}$ Ииимский педагогический институт им. П.П. Ершова (Филиал ТюМГУ),

Ииим, e-mail: anatoly_gerasrin@mail.ru;

${ }^{4}$ Тюменский индустриальный университет, Тюмень, е-таil: xelin102@gmail.com;

${ }_{5}^{5}$ Алтайский государственный педагогический университет, Барнаул, e-mail: harahordin62@mail.ru

Статья посвящена проблеме совершенствования технико-тактического мастерства в женском дзюдо. Цель исследования: обосновать методику использования резиновых амортизаторов и подбора удобного партнера для совершенствования техники выполнения броска «подхватом под две ноги» у девушек-дзюдоисток групп спортивного совершенствования в условиях учебно-тренировочных занятий. По классификации этот прием относится к группе бросков подворотом. При анализе научно-методической литературы выявлено в основном два подхода в освоении технического мастерства. Одни специалисты считают, что необходимо разнообразие в оснащенности техникой борцов-дзюдоисток, другие склонны к тому, что для достижения победы достаточно овладеть несколькими «коронными» приемами нападения. Для решения поставленных задач в повышении технического мастерства спортсменок нами был проведен педагогический эксперимент, в котором принимали участие 12 дзюдоисток групп спортивного совершенствования. На основе анализа научно-методической литературы и педагогического эксперимента показана эффективность применяемой методики с использованием резиновых амортизаторов и подбора на тренировке удобного партнёра при совершенствовании технического мастерства дзюдоисток. Оценка показателей освоенной техники броска «подхват под две ноги» осуществлялась экспертами из числа высококвалифицированных специалистов.

Ключевые слова: дзюдо, тренировка, эффективность подготовки, техника, бросок «подхват под две ноги»

\title{
THE METHODS TO IMPROVE SHOOTING TECHNIQUE «THE PICKUP UNDER TWO FEET» AT JUDOISTS ${ }^{1}$ Bobrovskiy V.A., ${ }^{2}$ Bobrovskiy A.V., ${ }^{1,4}$ Geraskin A.A., ${ }^{4}$ Moshkov M.K., ${ }^{5}$ Kharakhordin S.E. \\ ${ }^{1}$ Omsk State Technical University, Omsk,e-mail: bobrovskiy.av@mail.ru;
}

${ }^{2}$ Omsk Academy of the Ministry of the Interior of Russia, Omsk, e-mail: bobrovskiy.av@mail.ru;

${ }^{3}$ Ishim Pedagogical Institute named After P.P. Yershov (branch of TSU),

Ishim,e-mail: anatoly_gerasrin@mail.ru;

${ }^{4}$ Industrial University of Tyumen, Tyumen, e-mail: xelin102@gmail.com,

${ }_{5}^{5}$ Altai State Pedagogical University, Barnaul, e-mail:harahordin62@mail.ru

The article is devoted to the problem of improving technical and tactical skills in women's judo. The purpose of the study: to substantiate the method of using rubber shock absorbers and selecting a convenient partner for improving the technique of performing the throw «under two legs» in female judoists of sports improvement groups in the conditions of training sessions. The article is devoted to the problem of improving technical and tactical skills in women's judo. The purpose of the study: to substantiate the method of using rubber shock absorbers and selecting a convenient partner for improving the technique of performing the throw «under two legs» in female judoists of sports improvement groups in the conditions of training sessions.According to the classification, this technique belongs to the group of throws with a turn. The analysis of scientific and methodological literature revealed mainly two approaches to the development of technical skills. Some experts believe that it is necessary to have a variety of equipment for judo wrestlers, while others are inclined to believe that to achieve victory, it is enough to master several «crown» techniques of attack.To solve the tasks set in improving the technical skills of athletes, we conducted a pedagogical experiment in which 12 judoists of sports improvement groups took part.Based on the analysis of scientific and methodological literature and pedagogical experiment, the effectiveness of the method used with the use of rubber shock absorbers and the use of a convenient partner in training to improve the technical skills of judoka is shown. The assessment of indicators of the mastered technique of the throw «catch under two legs» was carried out by experts from among highly qualified specialists.

Keywords: judo, training, efficiency training, equipment, the cast of «the pickup under two feet»

В современном спорте активную позицию завоёвывают женщины. Об этом свидетельствует расширение программ Олимпийских игр и участие в них женщин. Международный олимпийский комитет обязал участвующие в Олимпиадах страны представлять женщин в видах спорта, считавшихся ранее исключительно «мужскими», таких как хоккей, тяжелая атлетика, футбол, бокс, дзюдо. Женщины участвуют 
в считавшихся ранее «мужскими» видах не только на олимпиадах, но и на чемпионатах мира, Европы по дисциплинам, которые не входят в Олимпийскую программу.

Напомним, что первый чемпионат Европы по борьбе дзюдо среди женщин был проведен в 1975 г. С 1980 г. проводятся чемпионаты мира. В 1988 г. женское дзюдо включено в программу Олимпийских игр. Активно развивается женское дзюдо и в нашей стране. В 1984 спорткомитетом СССР издан приказ «О развитии дзюдо среди женщин». Первый Всесоюзный турнир был проведен в 1985 г. Наши спортсменки, три Елены: Гущина, Петрова, Бесова, Светлана Бондаренко и Любовь Брулетова ярко выступили на первенствах Европы, мира и на Олимпийских играх. Удержание передовых позиций в этом направлении требует создания передовых подходов подготовки наших спортсменок, постоянного их совершенствования.

Настоящая работа направлена на совершенствование процесса техникотактической подготовки дзюдоисток. Традиционно научно-методические работы по дзюдо посвящались технико-тактической, физической, психической и другим видам подготовки юношеского и мужского контингента. С возникновением женского дзюдо возникла необходимость в научнометодических разработках по совершенствованию технико-тактического мастерства женщин-дзюдоисток.

Процесс становления женского дзюдо, формирование методики подготовки строились на основе опыта подготовки мужчин, c недостаточным учётом морфофункциональных, физиологических, психических и других свойств женского организма. Некоторые специалисты и в настоящее время не видят особой разницы в построении процесса технико-тактической подготовки мужчин и женщин. Принципиально возражая такому походу, отметим, что техника выполнения бросков у женщин отличается от мужской. Причиной различий являются разные уровни развития физических качеств. Женщины уступают мужчинам по силе и быстроте движений. Темп выполнения ими приемов медленнее. В связи с этим одной из основных задач при планировании содержания тренировочного процесса является направленность его на развитие физических качеств дзюдоисток, обеспечивающих повышение силового компонента и быстроты соревновательных действий.

В процессе подготовки необходимо учитывать физиологические особенности женского организма, особенности те- чения менструального цикла. Установлено, что у спортсменок он проходит с периодичностью от 21 до 35 дней, у 6\% через 42 дня. В это время проявляются индивидуальные особенности спортсменок. Некоторые испытывают эмоциональное напряжение, становятся раздражительными, могут создавать конфликты. У отдельных лиц может увеличиваться вес. Существует и преимущество женского организма - быстрое восстановление спортсменок после физических нагрузок. Эти факторы учитываются при построении тренировочного и соревновательного процессов.

Наш опыт свидетельствует, что технику приемов следует формировать в определённой последовательности. При изучении нового элемента необходимо вначале раскрыть занимающимся фазовую структуру (содержание) приема, учитывая рост, вес, другие индивидуальные особенности спортсменки. Далее - изучается технология выведения противника из равновесия рывком, толчком. Затем раскрываются особенности выполнения приема, в комбинации с ложными движениями, входа в прием и выполнения приема с преследованием на удержание, применения болевого приема, удушающего. Обучение технике приема должно проводиться индивидуально. С этой целью для разучивания или совершенствования приема подбираются специальные физические и имитационные упражнения, излагаются педагогические требования по их выполнению.

Основными приемами, применяемыми на соревнованиях в женском дзюдо, являются: подхват под две ноги, подхват под одну ногу, передняя подножка, бросок через спину, задняя подножка, броски с колен, подсечки, зацепы с вариантами разных захватов. Женщины редко применяют бросок через грудь. Причина этого - недостаточная физическая подготовленность. Это связано с тем, что мужской организм способен переносить более высокие нагрузки, на фоне которых выполняются технические действия в соревновательной обстановке. В связи с этим улучшение результатов выполнения того или иного технического приема существенно зависит от развития физических качеств.

Техника приема осваивается как раздельно (по частям), так и в целом. На начальном этапе важно подобрать для обучаемого удобного для тренировки партнера. Он должен соответствовать требуемой весовой категории, быть технически и тактически подготовлен, психологически совместим с обучаемым. Оба спортсмена должны соблюдать технику безопасности 
для исключения возникновения травм. Когда бросок освоен и выполняется технически правильно, рекомендуется увеличивать скорость его осуществления. Далее - выполнять прием на месте, затем в движении, с двумя партнерами, с партнером более тяжелого веса, с использованием резиновых амортизаторов. В годичном цикле подготовки объемная работа (набрасывания) используется в подготовительном периоде, а скоростная работа - в предсоревновательном и соревновательном периодах. Для развития скоростно-силовых способностей рекомендуется использовать метод круговой тренировки с использованием партнёров и дополнительных средств подготовки.

В единоборствах разработаны разнообразные упражнения, тренажерные средства для формирования физических качеств, совершенствования различных функций организма. Следует помнить, что высокие результаты достигаются при условии сбалансированного сочетания развития технической и физической подготовленности спортсменок. Уверенное выполнение технических действий - важнейший фактор психической подготовки, положительно влияющий на надёжность достижения спортивного результата. Здесь следует поддерживать у дзюдоисток проявления женской эмоциональности, агрессивного ведения схваток с соперницами, спортивной злости.

В настоящей работе предпринята попытка совершенствования процесса технической подготовки дзюдоисток, а именно - техники выполнения броска «подхват под две ноги», с использованием резиновых амортизаторов и партнеров, участие которых является эффективным средством подготовки к соревнованию.

Цель исследования - изучение эффективности методики совершенствования бросков подворотом, к которым относится подхват под две ноги у дзюдоисток групп спортивного совершенствования, с применением резиновых амортизаторов и партнеров, в условиях учебно-тренировочного процесса.

Объект исследования - учебно-тренировочный процесс занимающихся женским дзюдо в группах спортивного совершенствования.

Предмет исследования - методика применения комплекса упражнений, резиновых амортизаторов и партнёров для повышения эффективности техники выполнения бросков подворотом, в частности «подхвата под две ноги».

Гипотеза исследования: предполагалось, что разработка и применение методики использования специальных упражнений, с применением резиновых амортизаторов и партнеров, в условиях учебно-тренировочного процесса позволит существенно улучшить качество выполнения броска «подхват под две ноги» у дзюдоисток, занимающихся в группах спортивного совершенствования.

Методы исследования: анализ научнометодической литературы, педагогическое наблюдение, педагогический эксперимент, методы математической статистики.

\section{Результаты исследования и их обсуждение}

При анализе соревновательных поединков по дзюдо наблюдается, что отдельные спортсмены высокой квалификации имеют в своем арсенале всего несколько «коронных» технических действий. Как правило, это всего два-три приема, которые используются для достижения победы. Для проведения этих приемов в условиях состязаний опытными спортсменами используется большое число тактических решений - это специальная подготовка, подводка к завершению оцениваемого технического действия.

В большинстве своем тренеры в дзюдо стремятся, чтобы арсенал техники у учеников был как можно более разнообразным. Эта группа специалистов считает, что в первую очередь спортсменам необходимо избавиться от однотипных приемов и акцентировать внимание на разносторонности при совершенствовании технико-тактического мастерства [1-4]. Вторая группа утверждает, что выигрывать в борцовском поединке можно за счёт использования минимума хорошо отработанных технических действий. Другими словами, для достижения победы борцу достаточно нескольких «коронных приёмов» [5; 6]. На наш взгляд, правильность решения данной проблемы находится где-то посредине. То есть дзюдоист должен быть оснащён достаточным арсеналом технико-тактических действий и в то же время владеть в совершенстве несколькими излюбленными приёмами.

Высокую значимость имеет психическая подготовка дзюдоисток. В ответственных моментах состязания она имеет решающее значение для победы над равным по подготовленности соперником. В спорте высших достижений в финальной части соревнований всегда встречаются участники технически и физически высоко подготовленные. Победителями здесь, как правило, становятся эмоционально устойчивые, психически готовые к жесткой соревновательной деятельности спортсмены.

В современных единоборствах в процессе подготовки активно используются 
тренажерные и различные вспомогательные средства для развития физических качеств и совершенствования технико-тактического мастерства [7-9]. В спортивной борьбе для имитации приёмов часто применяют резиновые амортизаторы. Преимущество использования этого элемента тренировочных воздействий - в доступности, мобильности, быстроте подготовки для тренировки, возможности увеличения или уменьшения величины сопротивления действиям спортсмена, легкости изменения углов направленности воздействия на условного противника. Следует помнить, что в каждом виде борьбы имеется определённая специфика применения упомянутых тренажёрных средств.

В предлагаемом подходе спортсменка выполняет захват за резиновые амортизаторы, создающие сопротивление для проведения броска, когда атакующая находится в стартовом положении. Новизна подхода состоит в том, что в зависимости от решаемых задач резиновый амортизатор крепится не только к неподвижной опоре, но и непосредственно к партнеру. Это вынуждает атакующего прикладывать дополнительные усилия при моделировании соревновательных действий. Таким образом, осуществляется параллельная работа по совершенствованию техники и тактики соревновательных действий и развитию специальной физической и психической подготовленности.

На практике содержание методики заключалось в следующем. Атакующая дзюдоистка выполняет двойной захват одновременно за кимоно партнера и за резиновый жгут, закрепленный за спиной защищающегося, на неподвижной опоре, например на шведской стенке. Захват осуществляется обеими руками. Далее выполняется тяга, по технике соответствующая проведению броска «подхват под две ноги». Это упражнение используется также для всех бросков «подворотом» вперед.

При совершенствовании техники дзюдоистки выполняли данное упражнение несколькими сериями (4-5 серий), по 10 повторений. Отдых составлял 7-8 минут. Упражнения выполнялись равномерно и с ускорениями. По времени и темпу работы упражнения выполняли следующим образом: 25 сек. равномерно, 15 сек. ускоренно; 20 сек. равномерно, 10 сек. ускоренно. На начальном этапе применялись несложные варианты упражнений. По мере освоения техники варианты заданий усложнялись:

- резиновый амортизатор закреплен за шведскую стенку, концы его свободны для захвата;
- необходимо отшагнуть, создать натяжение амортизатора;

- выполняются подвороты для бросков вперед, сначала в медленном темпе (через бедро, через спину, подхватом), затем скорость постепенно увеличивается до максимальной;

- выполняется 20 подворотов в правую сторону и 20 - в левую. При этом резиновый жгут спортсменка держит в напряжении;

- постепенно увеличивается степень сопротивления амортизатора, увеличивается и скорость выполнения упражнений.

При выполнении заданий тренера-преподавателя, связанных с применением резиновых амортизаторов, необходимо следить за правильным захватом жгута. Концы амортизаторов должны быть взяты кистями рук обычным хватом, без скручивания. При выполнении упражнений важно добиваться правильного сочетания работы рук и ног.

Для достижения цели исследования проведён педагогический эксперимент, на базе БУ СШОР-17 г. Омска, в группах спортивного совершенствования девушек, занимающихся дзюдо. Педагогический эксперимент длился 3 месяца, на этапе специальной подготовки. В исследовании принимали участие 12 квалифицированных дзюдоисток. Для определения эффективности предлагаемой методики в начале и в конце эксперимента проводилась экспертная оценка совершенствуемых технических действий. Экспертную оценку осуществляли тренеры-преподаватели, имеющие высшую квалификационную категорию.

Критерии оценки были следующие:

- правильность выполнения техники броска;

- быстрота (скорость) выполнения упражнений за заданное время тестирования.

Временные показатели измерялись по шкале, представленной следующим образом:

- выполнение бросков за 30 сек. 10 и более бросков - 5 баллов;

- выполнение бросков за 30 сек. 7-8 бросков - 4 балла;

- выполнение бросков за 30 сек. 5-6 бросков - 3 балла.

Оценка правильности выполнения технического действия проводилась следующим образом:

- движение выполнено целостно, быстро, сильно, с высокой амплитудой 5 баллов;

- бросок выполнен с небольшими техническими погрешностями, немного нарушена целостность движения - 4 балла;

- бросок выполнен со значительными ошибками - 3 балла. 
Таблица 1

Экспертная оценка выполнения техники броска «подхватом под две ноги» до и после проведения эксперимента

\begin{tabular}{|c|c|c|c|c|c|c|}
\hline $\begin{array}{c}\text { Экспериментальная } \\
\text { группа (чел.) }\end{array}$ & \multicolumn{3}{|c|}{ Экспертная оценка } & \multicolumn{3}{|c|}{$\begin{array}{c}\text { Экспертная оценка } \\
\text { до эксперимента (чел.) }\end{array}$} \\
\cline { 2 - 7 } & «отлично» & «хорошо» & «удовл.» & «отличноле экспимента (чел.) \\
\hline 12 & 3 & 4 & 5 & 6 & 5 & 1 \\
\hline
\end{tabular}

Приемы выполнялись спортсменками в тройках. То есть дзюдоистку, проводящую бросок «подхватом под две ноги», атакуют два партнера. Такой подход приучает к проведению технических действий с высокой интенсивностью.

По данным контрольного тестирования участвовавшие в исследовании дзюдоистки распределились по группам в зависимости от результатов тестирования (табл. 1).

При подведении итогов педагогического эксперимента определены качественные показатели освоения и совершенствования технико-тактических действий при выполнении броска «подхватом под две ноги» с использованием резиновых амортизаторов и партнера. Как видно из данных табл. 1, до начала эксперимента испытуемыми были показаны следующие результаты. Из 12 дзюдоисток только 3 спортсменки выполняли задание с оценкой «отлично», 4 человека - с оценкой «хорошо» и 5 человек получили оценку «удовлетворительно». Такие результаты не могли удовлетворить требованиям педагогов к подготовленности занимающихся.

По завершении педагогического эксперимента, где применялась разработанная методика, установлено, что участницы исследования значительно улучшили результаты тестирования технико-тактической подготовленности.

При сравнении результатов 1-го и 2-го этапов исследования (табл. 2) наблюдается совпадение парных отношений в пяти случаях. Несовпадение в пользу второго обследования обнаружено в семи случаях $(0-5, \mathrm{n}=12-5=7)$. Критерий знаков $\mathrm{z}$ : при $0,05 \%$ уровне вероятности событий $\mathrm{n}$ фактическая -7 , равна $\mathrm{n}$ стандартной -7 . Следовательно, уровень качества выполнения бросков улучшился достоверно [10, c. 231-232], табл. 2.

Закономерность нового положительного состояния подготовленности испытуемых подтверждается применением математических расчётов путём вычисления коэффициента ранговой корреляции по К. Спирмену - количественной оценки изучения связи между исследуемыми непараметрическими показателями. Коэффициент корреляции рангов Rs $=0,838$ (при $\mathrm{n}=12, \mathrm{Rs}=0,58)[10$, c. 238-242]. Установленный коэффициент ранговой корреляции статистически значим, имеется высокая достоверная положительная корреляционная связь между уровнем качества выполнения данного броска «подхватом под две ноги» у дзюдоисток при сравнении традиционной и экспериментальной методик спортивной подготовки.

Можно констатировать, что полученные данные свидетельствуют о достоверности различий между группами и достижении более высокого уровня технической подготовленности дзюдоисток на втором этапе исследования эффективности методики совершенствования действий при бросках «подхватом под обе ноги» с использованием резиновых амортизаторов и привлечением для тренировки различных партнёров.

Таблица 2

Ранговая таблица зависимости выявленных показателей подготовленности дзюдоисток

\begin{tabular}{|c|c|c|c|}
\hline Испытуемый & 1 оценка & 2 оценка & Различия \\
\hline 1 & 5 & 5 & 0 \\
\hline 2 & 5 & 5 & 0 \\
\hline 3 & 5 & 5 & 0 \\
\hline 4 & 4 & 5 & 1 \\
\hline 5 & 4 & 5 & 1 \\
\hline 6 & 4 & 5 & 1 \\
\hline 7 & 4 & 4 & 0 \\
\hline 8 & 3 & 4 & 1 \\
\hline 9 & 3 & 4 & 1 \\
\hline 10 & 3 & 4 & 1 \\
\hline 11 & 3 & 4 & 1 \\
\hline 12 & 3 & 3 & 0 \\
\hline
\end{tabular}

\section{Заключение}

Анализ научной и методической литературы по проблеме совершенствования технико-тактического мастерства женщин-дзюдоисток свидетельствует, что в большинстве исследований используется методика, применяемая при подготовке мужчин-дзюдоистов, без учёта различий особенностей мужского и женского организма: более слабой физической под- 
готовленности женщин в сравнении с мужским контингентом; влияния жизненного цикла на самочувствие спортсменок и их психическое и физическое состояние; возможностей использования эмоционального подъёма у спортсменок при подготовке и выступлениях на состязаниях, более быстрой восстанавливаемости женского организма после нагрузок.

Выявлены два традиционных подхода, используемых специалистами при формировании «набора» элементов техники борцов. При первом дзюдоист осваивает возможно большее число приемов, обеспечивая разнообразие технико-тактических действий, которые используются в зависимости от подготовленности и действий противника, хода соревновательных ситуаций.При втором подходе борец овладевает несколькими хорошо отработанными, «коронными» приемами, которыми он пользуется для достижения победы. Оба подхода имеют как положительные стороны, так и недостатки. В первом случае освоение многообразия приёмов не позволяет сформировать у занимающегося в достаточной мере навыки выполнения коронных приёмов. Второй подход ведёт к некоторому однообразию в ведении тактики поединков, давая возможность сопернику быть готовым к использованию дзюдоистом известных соревновательных действий. Истина, на наш взгляд, находится в «золотой середине». Она состоит в том, что дзюдоисту или дзюдоистке необходимо освоить достаточный арсенал технико-тактических действий и в то же время иметь несколько излюбленных, надёжных и результативных приёмов. Это позволит дзюдоисту вести борьбу с разнообразием тактических действий соперника, с опорой на надёжность и точность исполнения своих коронных приёмов.

Для исследования эффективности предлагаемой методики проведен педагогический эксперимент. Экспертная оценка комиссии специалистов из тренеров-преподавателей высшей категории установила, что применение комплекса специальных упражнений, использование резиновых амортизаторов в процессе подготовки дзюдоисток высокой квалификации, взаимодействий с одним-двумя подобранными партнёрами позволяет существенно улуч- шить технику выполнения броска «подхватом под две ноги».

Методика может применяться в специализированных детско-юношеских спортивных школах. Она способствует улучшению техники борьбы, позволяет тренеру в процессе совершенствования приемов вносить различные сочетания заданий по усложнению деятельности, адресно направлять педагогические воздействия на формирование выносливости или силовой подготовленности либо на развитие быстроты и точности двигательных действий дзюдоисток, учитывая индивидуальные особенности их организма. Практика применения экспериментальнойметодики свидетельствует, что она может с успехом использоваться при совершенствовании всех видов бросков «Подворотом».

\section{Список литературы}

1. Аккуин А.Д. Методика повышения надежности выполнения технических действий дзюдоистов в условиях соревновательной деятельности // Ученые записки университета им. П.Ф. Лесгафта. 2017. № 8 (150). С. 7-11.

2. Еганов А.В. Теория и методика спортивной тренировки дзюдоистов: монография. М., 2014. 212 с.

3. Элипханов С.Б. Особенности мышечной активности при проведении броска выхватом за бедро изнутри высококвалифицированными дзюдоистками // Вестник Майкопского государственного технологического университета. 2012. № 3. C. 111-115.

4. Андрущишин И.Ф., Шепетюк М.Н., Райфова Р., Житкеев А.Р., Шепетюк Н.М. Развитие скоростно-силовых качеств дзюдоисток высокой квалификации на этапе специальной подготовки // Наука и спорт: современные тенденции. 2015. Т. 7. № 2. С. 105-109.

5. Андрущишин И.Ф., Сапиев С.Ж., Гераськин А.А., Денисенко Ю.П. Сравнительный анализ особенностей личности боксеров различного уровня // Рудиковские чтения 2019: материалы XV Всероссийской научно-практической конференции с международным участием/ Под общ. ред. Ю.В. Байковского, В.А. Москвина. 2019. С. 9-13.

6. Иванков Ч.Т., Сафошин А.В., Гасанов Р.Г., Умаров М.К. Рационализация техники атакующих действий в спортивной борьбе на примере дзюдо // Наука и школа. 2016. № 2. C. 207-212.

7. Тищенков И.И., Извеков В.В., Извеков К.В. Дзюдо и самбо среди женщин: методика подготовки спортсменок. Саранск, 2017. 56 с.

8. Бобровский В.А., Кладов Э.В., Мартыненко А.Н., Бобровский А.В. Методика оценки уровня развития специальной выносливости единоборцев // Психопедагогика в правоохранительных органах. 2017. № 2. С. 64-67.

9. Елисеев Е.В., Трегубова М.В., Абрамов Д.С. Факторы роста физической работоспособности единоборцев в динамике их физического развития и подготовленности // Фундаментальные исследования. 2014. № 1. С. 55-58. $352 \mathrm{c}$ 